preparation of potash should $\mathrm{h} c$ given, or whether different salts should he combined, I must say I have not been able to determine. As we know that they almost all leave the system as carbonates, the presumption is that no important difference exists as to their effects on the system. This point, however, must still be considered sub judice. The alkaline treatment, then, of rheumatic fever, I consider as taking the very first place; of course modified in the extent to which it is carried by the lemands of each case. On this point I go the entire way with two London physicians, Drs. Garrod and Fuller, who have each written most ably on the matter. The paper, indeed, of the former appears to me absolutely conclusive; and yet, strange to say, I believe it was not even alluded to in the late discussions in London.

Forcibly, however, as I would wish to bring under your notice the aikaline treatment of the disease, I am very far from saying that it is all that is required. You all know that the affection is one which very crenerally, though not always, entails severe suffering. All suffer pain, fut some a great deal more than others. Now, in all these cases I have been in the habit, for some years past, of giving anodynes in union with the alkalics, opium being the chief, and, when it agrees, by far the best. The opiate treatment has been long known; but I am not sure I have anywhere seen the combined plans recommended; and yet, with my present experience, I believe it to be the best and safest jlan which can be adopted. It acts tuto, cito, et jucunde.

In these very brief remarks on the treatment of acute rheumatism, I have purposely omitted many points both of moment and interest, as well as treatment. To one point only, before concluding, I may allude - that is, whether the alkaline treatment lessens the probability of the heart becoming engaged. I believe it does. But this is a point on which it must be allowed a great caution would be required, before riving an opinion. If, however, a certain line of treatment lessens the duration of this disease, it would be fair to infer that it must, by so much, diminish the chance of the heart getting engaged; and this would seem to be confirmed by any statistics yet brought to bear on the question. Within my own observation, the heart, when attacked at all, has, in the great majority of instances, been affected before the patients came into hospital; and it has been the valves, not the pericardium, which were involved. It is worth noting that I have, in four instances, seen pericarditis precede the affection of the joints.

To sum up, then, I hold that acute rheumatic fever can, by our art, be materially shortened in its duration, and that those who are sick need a physician.

\section{REMARKS ON THE TREATMENT OF DIABETES.}

By F. W. PAVY, M.D., F.R.S.,

Senior As: istant-Physician to, and Lecturer on Physiology at, Guy's Hospital.

Contained in the number of the British Medical Journal for 1 pril Ioth, I noticed a communication from Dr. Basham, entitled "Obscrvations on the Successful Treatment of Diabetes by Alkalies and the Phosphatic Salts of Ammonia, with Limited Restriction of Diet." A case which I brought forward at the Clinical Society towards the close of last year, that had been treated successfully without restriction of liet, is there alluded to. The medicinal agents administered in this case consisted of opium in increasing doses until the quantity reached twelve grains $p$, dicm, and a mixture containing the bicarbonate of potash and aromatic spirit of ammonia.

What is said by Dr. Basham leads me to offer a few remarks, because the inference is conveyed that the result might have been attributable to the alkalies, and not to the opium. I am quite ready to admit that it would have been more satisfactory for the sake of conclusiveness if the alkalies had not been administered; but I am at the same time convinced, from what I have seen in other cases, that they had little or nothing to do with the rapid arrest of the discharge of sugar that occurred.

I know of no medical agent that is capable of exerting a controlling influence over the complaint like that exerted by opium. In common with others, I have employed alkalies and ammonia largely in diabetes, and am well familiar with the kind of effect to be looked for. I have been of opinion that they produce a slowly beneficial action in the complaint; but never have I observed any immediate effect of a marked nature that could be attributed solely to their influence. With opium, on the other hand, the effect is so striking, that there can be no question of its reality. In my communication to the Clinical Society, besides the case above alluded to, two others were mentioned, in both of which the sugar was removed-in the one instance by opium, and in the other by morphia. In these cases, there was no other agent administered. They were cases of the disease in middle-aged subjects. The sugar was reduced as far as it could be by a restricted diet; and then, under the influence of the morphia and opium, it was entirely removed. There is also at the present time a patient at No. I bed in John Ward, Guy's Hospital, a most instructive case bearing on the point ir question. It is the same patient to whom $I$ administered the ozonic ether without observing any beneficial effect, and whose case, in reference to this agent, I mentioned in the Lancet a few weeks ago. The man, a middle-aged person, was passing, under a restricted diet, about six pints of urine, containing upwards of three thousand grains of sugar, in the twenty-four hours. At first, after the ozonic ether had been discontinued, morphia was administered in gradually increasing doses, beginning with half a grain three times a day. The quantity of urine and sugar from day to day declined, and, in the space of about three weeks, disappeared altogether; the quantity of morphia administered at this time being a grain and three-quarters three times a day. After a little while, the morphia was taken off; and in a week's time the sugar began to reappear, and went on from day to day increasing. This state of things was allowed to continue for about a fortnight, when opium was given; and, under its influence, the sugar has again disappeared. I merely here allude to this case; the patient, being still in the hospital, may be seen by any one desirous of doing so.

Of what service as a curative agent, opium, in larger doses than it has been customarily given, may prove in cases in general, I do not at present pretend to say. Much more extended observation is required before this point can be determined. Whatever may happen to be disclosed by subsequent experience, it cannot be denied, I think, that we have before us an important therapeutic fact. The woman whose case formed the basis of my communication to the Clinical Society has been seen by me from time to time up to as recently as a fortnight back. She has taken no opium or other kind of medicine since October last; has been living (as she did when under treatment) upon an ordinary mixed diet; and has been passing urine devoid of sugar. Her case, in fact, up to the present time, forms an example of a direct and perfect cure.

I have a patient under treatment, also in John Ward, to whom I have been lately giving the carbonate of ammonia to a much larger extent than it is usually administered. One hundred grains in the twenty-four hours have been taken. At the commencement, it was given without a restricted diet; then discontinued; and, after the patient had been for a few days upon a restricted diet, given again. At first, the effect observed was an increase both in the amount of urine and sugar. Since, however, a marked improvement has occurred; but, if space be accorded me in the BRITISH MEDICAL JOURNAL, I will, in one of the forthcoming numbers, supply a detailed report of the case.

\section{DISLOCATION OF THE SEMILUNAR BONE OF THE CARPUS.}

\section{By R. P. B. TAAFFE, M.D., Brighton.}

A SHORT time since, the sprite at the Brighton Theatre, in one of his performances on a trapeze, fell from a height of about twenty feet. $\mathrm{He}$ fell on his side; and, according to the statements of his fellow-performers, he rebounded from the stage about two feet. In his fall, he struck the back of his hand violently against the stage. On looking at the wrist, there appeared to be some amount of deformity. On close examination, it was found that there was dislocation of a single bone of the carpus, which projected prominently forwards and upwards between the radius and ulna; it was not wedged between the bones, but projected in front of them on the anterior aspect of the limb. The radius and ulna were not displaced; nor was there any evidence of fracture.

I saw the case within ten minutes after the accident, and before any swelling had taken place. I was enabled to reduce the dislocation by means of strong extension and firm pressure, without chloroform. When last seen, the movements of the wrist were not impaired, and there was no recurrence of the dislocation on flexion or extension of the joint.

From the situation of the dislocated bone, and its being quite free, without any displacement or fracture of the radius or ulna, and its being reduced by pressure inwards and downwards, it could have been no other than the semilunar bone.

Mr. Erichsen records a case of dislocation of the semilunar bone on the dorsal aspect of the carpus. The peculiarity of the case I relate is, that the bone was displaced anteriorly, and thrown some distance above the carpus (about half an inch), and into the forearm. 